\title{
15 YEARS OF PARAGANGLIOMA Pathology of pheochromocytoma and paraganglioma
}

\author{
Arthur S Tischler and Ronald R deKrijger ${ }^{1,2}$ \\ Department of Pathology and Laboratory Medicine, Tufts Medical Center, Tufts University School of Medicine, \\ 800 Washington Street, Box 802, Boston, Massachusetts 02111, USA \\ ${ }^{1}$ Department of Pathology, Erasmus MC University Medical Center, Rotterdam, The Netherlands \\ ${ }^{2}$ Department of Pathology, Reinier de Graaf Hospital, Delft, The Netherlands
}

Correspondence should be addressed to A S Tischler Email atischler@tufts medicalcenter.org

\begin{abstract}
Pathologists using their routine diagnostic tools can contribute both to the care of patients with pheochromocytoma/paraganglioma and to understanding the pathobiology of the tumors. They can document details of tissue organization and cytology that are accessible only by microscopy and can characterize admixtures of cell types that are morphologically distinct or show differential expression of immunohistochemical markers. Current roles and challenges for pathologists include differential diagnosis, identifying clues to the presence of hereditary disease, and effective communication of pathology information for clinical and research purposes. Future roles will increasingly involve risk stratification, identification of actionable targets for personalized therapies, and aiding the interpretation of molecular tests by helping characterize genetic variants of unknown significance. It remains to be determined to what extent the need for pathology input will be overshadowed by the availability of genetic testing and other molecular analyses at ever-decreasing cost, together with very effective clinical paradigms for risk stratification and patient care.
\end{abstract}

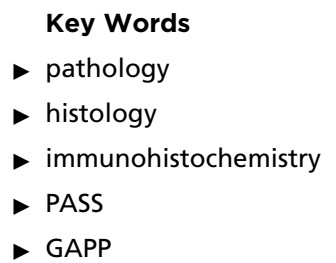

Endocrine-Related Cancer (2015) 22, T123-T133

\section{Introduction}

Endocrine Related Cancer made its debut March 1994. The revolutionary genetic advances that were to change the face of medicine were just beginning to accelerate. Only three genes, NF1, RET, and VHL (Neumann et al. 1993, Bausch et al. 2006), were known to be associated with pheochromocytomas, all with well-defined syndromic manifestations, and the genetic associations of extraadrenal paragangliomas had not been determined. The main role of pathology was to make a correct diagnosis. Because the $10 \%$ rule held sway, most of the tumors were considered to be benign and sporadic and, because there was no way to identify the $10 \%$ destined to metastasize, for most pathologists the job was essentially done once the diagnosis was made.
The $10 \%$ rule was definitively overturned in 2002 (Neumann et al. 2002), following the discovery that hereditary head and neck paragangliomas were caused by mutations of SDHD (Baysal et al. 2000). It is now recognized that at least $40 \%$ of pheochromocytomas/ paragangliomas are hereditary, and at least 19 susceptibility genes have been identified, along with an expanding spectrum of syndromically associated abnormalities (Favier et al. 2015, Pacak \& Wimalawansa 2015). Further, some of the new hereditary pheochromocytomas and paragangliomas do not have syndromic manifestations, while occult germline mutations of classic susceptibility genes are identified in some patients in whom the tumors are apparently sporadic (Neumann et al. 2002).

This paper is part of a thematic review section on 15th Anniversary of Paraganglioma and Pheochromocytoma. The Guest Editors for this section were Wouter de Herder and Hartmut Neumannn loaded from Bioscientifica.com at 04/26/2023 11:10:14AM 
In addition, somatic mutations of hereditary susceptibility genes are increasingly found in tumors that are truly sporadic and can contribute to tumorigenesis but so far have no further clinical impact (Dahia 2013, Pacak \& Wimalawansa 2015).

It is now recognized that metastatic potential and patient outcomes vary with genotype of hereditary pheochromocytoma/paraganglioma, and pathologists have begun to search for both morphological and immunohistochemical markers that would stratify primary tumors according to risk of metastasis or correlate with specific genotypes. In that context, immunohistopathology expanded from its classic role as a diagnostic tool to include molecular genetic immunohistopathology, helping predict what mutation is present.

Because of the recent knowledge explosion, pathologists now face challenges and opportunities in several areas. In addition to diagnosis, these include: identification of clues to the presence of hereditary disease, risk stratification, identification of drugable targets for personalized therapies, and effective communication of pathology information for clinical and research purposes. Progress has been made in each of these areas, as summarized in this review. Nonetheless, it remains to be determined to what extent the need for pathology input will be overshadowed by the availability of genetic testing and other molecular analyses at ever-decreasing cost, together with very effective clinical paradigms for risk stratification and patient care.

The roles of pathology in management of patients with pheochromocytomas and paragangliomas are currently in flux, and it is noteworthy that the 2014 clinical practice guidelines published by the Endocrine Society did not include any specific role (Lenders et al. 2014). However, in a subsequent letter the drafters of the guidelines pointed out that there is a clear need for standardized pathology reporting, especially to facilitate the use of pathology data in cross-disciplinary multicenter studies. Those studies would in turn help define evidencebased roles of pathology for inclusion in future guidelines (Mete et al. 2014b).

\section{Differential diagnosis}

The diagnosis of pheochromocytoma or paraganglioma can usually be rendered, or at least entertained, using H\&E stained sections. However, the maxim that 'the first step in a diagnosis is to think of it' pertains to pathology as well as clinical practice. One important element of preparedness is to be familiar with the anatomic distribution of paraganglionic cells and tissues along branches of peripheral sympathetic nerves and cranial nerve branches in the head and neck (Tischler 2012). A second is familiarity with the range of histological and cytological appearances that pheochromocytomas and paragangliomas can present, often in different areas of the same tumor.

The majority of tumors exhibit the classic 'Zellballen' described in normal paraganglia by the anatomist Alfred Kohn in the late 19th century. These structures are nests of tumor cells separated by peripheral capillaries. A second cell population called sustentacular cells can be demonstrated at the periphery of the nests by immunohistochemical staining for S100 protein (Fig. 1). Varied functions have been proposed for sustentacular cells in normal paraganglia, including serving as stem cells (Rubin de Celis et al. 2015) and as glial-like supporting cells. In pheochromocytoma/paraganglioma it is debated whether they are neoplastic or benign migrants from adjacent tissue or the circulation (Douwes Dekker et al. 2004).
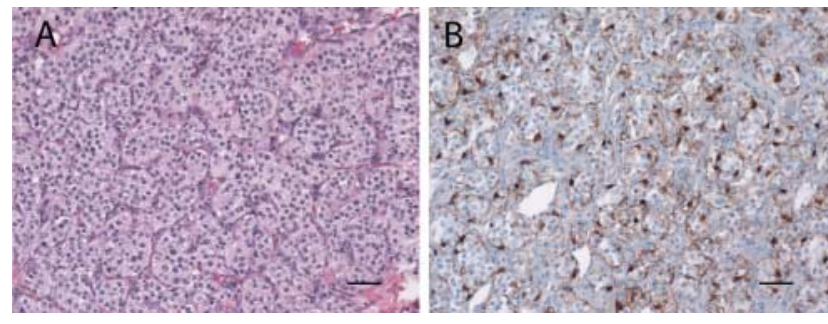
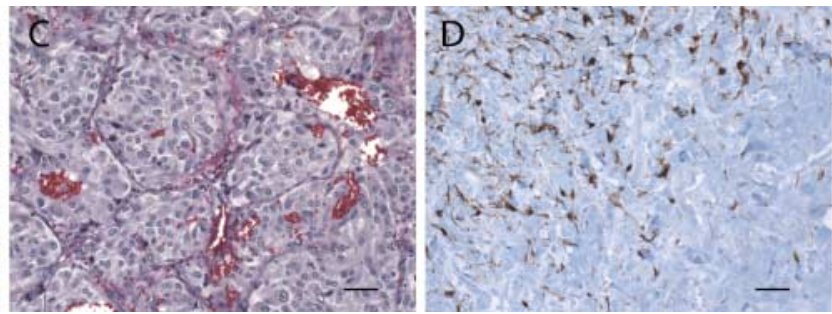

Figure 1

A vagal paraganglioma $(A, B)$ and pheochromocytoma $(C, D)$ showing characteristic 'Zellballen' architecture in H\&E sections ( $A$ and $C$ ) and sustentacular cells in sections stained for $\mathrm{S} 100$ protein (B and D). Although the architecture is similar, there can be substantial variation in cell size as in these two examples. Also as shown, Zellballen are often more pronounced in parasympathetic than in sympathoadrenal paragangliomas. Sustentacular cells are classically seen at the periphery of Zellballen (B) but can also be interspersed between tumor cells and can be very unevenly distributed within a tumor (D). Bars $=50 \mu \mathrm{m}$. http://erc.endocrinology-journals.org DOI: $10.1530 /$ ERC-15-0261
(C) 2015 Society for Endocrinology Printed in Great Britain
Published by Bioscientifica Ltd 
Variations in tumor architecture include diffuse and trabecular growth patterns, extensive sclerosis creating patterns that mimic invasive carcinoma (Fig. 2A), and unusual vascular patterns that can mimic angiomas. Cavernous blood vessels can be particularly prominent in head and neck paragangliomas (Fig. 2B). Cytologically, pheochromocytoma or paraganglioma cells can closely resemble normal chromaffin cells or can be smaller or larger. The latter frequently have vesicular nuclei with prominent nucleoli resembling the nuclei of neurons, but have no processes and contain numerous secretory granules similarly to other neoplastic chromaffin cells. Clear cells can be particularly prominent in primary or metastatic paragangliomas, particularly those arising in the head and neck. These can be confused with squamous cell carcinomas, which are common in the same region. Because head and neck paragangliomas are often caused by $S D H x$ mutations, the clear cytoplasm is possibly attributable to upregulation of glucose transporters by hypoxia-inducible transcription factors and increased lipid synthesis (Teicher et al. 2012). Pigmented pheochromocytoma and paraganglioma are sometimes encountered (Fig. 2C) and must be distinguished from melanomas (Bellezza et al. 2004). Names have been proposed for specific 'variants' of pheochromocytoma and paraganglioma, e.g., angiomatous, sclerosing, and small cell variants, but these have no significance other than as reminders of various morphologies to be considered in differential diagnosis. In addition to these architectural and cytological variations, pheochromocytomas or paragangliomas are occasionally encountered as composite tumors admixed with neuroblastoma, ganglioneuroblastoma, or malignant peripheral nerve sheath tumor (Tischler 2000). One admixed tumor that is probably misnamed and should not be considered a paraganglioma at all is 'gangliocytic paraganglioma' of the duodenum, an admixture of mature neurons, Schwann cell-like spindle cells, and low-grade GI-type neuroendocrine tumor cells that typically express keratins, pancreatic polypeptide, and somatostatin (Burke \& Helwig 1989).

Pheochromocytomas or paragangliomas can present diagnostic challenges either in relation to similar appearing tumors that arise in close anatomic sites or because of unusual histologic features. Diagnosis can be particularly difficult when they develop in unusual locations such as thyroid (von Dobschuetz et al. 2015) or ovary (Schuldt et al. 2015). Immunohistochemistry is used as an aid to diagnosis in challenging cases, with the immunohistochemical markers tailored to both the anatomic site and the diagnoses under consideration. As general guidelines,
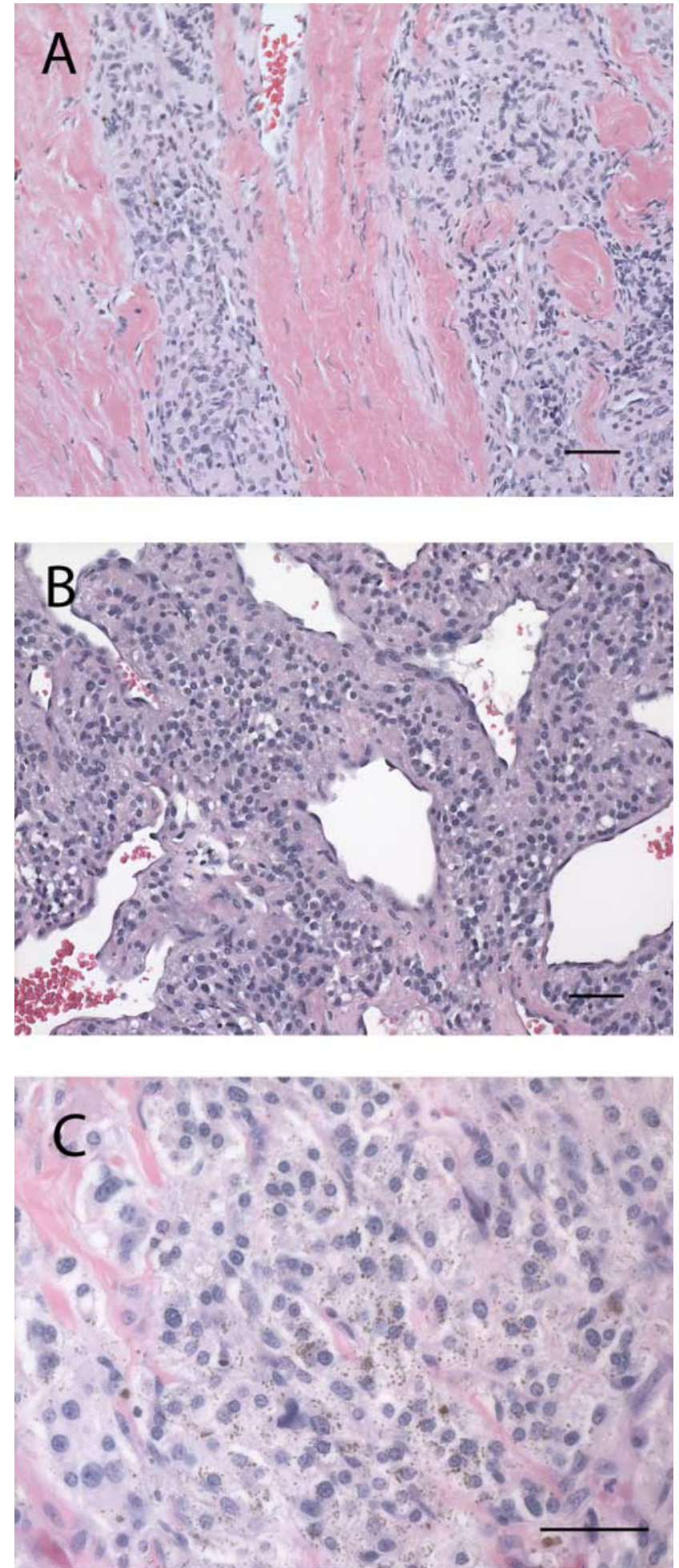

Figure 2

Representative potential challenges in differential diagnosis include sclerosing patterns mimicking infiltrating carcinoma (A), cavernous blood vessels mimicking vascular neoplasms $(B)$, and pigmentation mimicking melanoma (C). Cavernous blood vessels are particularly common in head and neck locations, as in the vagal PG shown. Bars $=50 \mu \mathrm{m}$.

Published by Bioscientifica Ltd. 
pheochromocytomas and paragangliomas express generic neuroendocrine markers, of which chromogranin A and synaptophysin are most often utilized, and are usually negative for keratins, which helps distinguish them from other neuroendocrine tumors. Expression of tyrosine hydroxylase is useful as a more specific paraganglionic marker. In the thyroid, absence of staining for calcitonin is an important site-specific criterion to distinguish paragangliomas from medullary thyroid carcinomas (von Dobschuetz et al. 2015).

Several caveats pertain to the selection of immunohistocemical markers for differential diagnosis. First, it should be borne in mind that synaptophysin is less specific than chromogranin A is and can be expressed in adrenal cortical (Sangoi \& McKenney 2010) and other tumors. Second, while pheochromocytomas and sympathetic paragangliomas are diffusely positive for chromogranin A and tyrosine hydroxylase, head and neck paragangliomas can be completely negative or only focally positive for both and sometimes preferentially express chromogranin B (Schmid et al. 1994). The absence of tyrosine hydroxylase accounts for the usual non-functionality of these tumors and their historical designation as 'non-chromaffin paragangliomas'. In addition, focal keratin expression is occasionally seen in both sympathetic and head and neck paragangliomas (Johnson et al. 1988, Chetty et al. 1998, Labrousse et al. 1999). Immunostaining of sustentacular cells for $\mathrm{S} 100$ can be helpful in diagnosing paragangliomas but is not specific because these enigmatic cells can also be present in other neuroendocrine tumors (Gosney et al. 1999).

\section{Clues to genetic disease}

Pathologists can make an important contribution to patients and their families by finding clues to the presence of hereditary disease in individuals presenting with solitary tumors and no relevant history. Historically, this role related mostly to MEN2 and was accomplished by carefully examining adrenal specimens with pheochromocytomas for adrenal medullary hyperplasia and examining thyroid specimens with medullary thyroid carcinoma for C-cell hyperplasia. A welcome recent development regarding MEN2 is the proof that small adrenal medullary nodules, which were arbitrarily classified by some authors as hyperplastic if they measured $<1 \mathrm{~cm}$, are in fact micro-pheochromocytomas and are more appropriately classified as such (Korpershoek et al. 2014). This finding is consistent with an earlier report based on methylation of androgen receptor alleles in female patients showing that the nodules were usually monoclonal and, interestingly, that all monoclonal nodules from the same patient showed inactivation of the same X-chromosome (Diaz-Cano et al. 2000). The relationship between adrenal medullary nodules and diffuse adrenal medullary hyperplasia is still unclear. However, pheochromocytomas, whether micro or macro, can develop in MEN2 patients without obvious diffuse hyperplasia (Tischler 2008a).

In addition to MEN2, the finding of multicentric and bilateral pheochromocytomas and adrenal medullary nodules now suggests the possibility of germline mutations in the TMEM127 gene (Toledo et al. 2015). As in MEN2, patients with TMEM127 mutations typically do not develop paragangliomas. Aside from the adrenal changes in MEN2 or TMEM127 adrenals, morphological findings in a pheochromocytoma or paraganglioma seldom provide clues to hereditary status or to a specific genotype. Patients with VHL disease sometimes present with more than one pheochromocytoma, and the tumors have been reported to be characterized by a thick vascular capsule and small- to medium-sized tumor cells with amphophilic clear cytoplasm and numerous interspersed small vessels (Koch et al. 2002). However, these findings are variable. In addition, the cytoplasmic qualities can be affected by tissue fixation and processing. The features described are therefore more reliable for discriminating between MEN2 and VHL in a patient with multiple tumors than for characterizing a tumor that is solitary and apparently sporadic.

There is now an expanding hereditary pheochromocytoma/paraganglioma sprectrum that includes both new susceptibility genes and syndromes, and pheochromocytomas or paragangliomas that are hereditary but not syndromic. Further, there is overlap between classic and new syndromes and between the classic syndromes themselves. Examples include renal cell carcinomas, formerly thought of mainly in VHL, and pituitary adenomas, formerly thought of mainly in MEN1, as components of hereditary syndromes caused by $S D H x$ mutations (Pasini \& Stratakis 2009, Xekouki et al. 2015). Gastrointestinal stromal tumors (GISTs), which occur often in patients with NF1 (Agaimy et al. 2012), are also important components of $S D H \mathrm{x}$-related syndromes (Pasini \& Stratakis 2009). Renal cell carcinomas have also been reported both in association with mutations of another Kreb's cycle gene, fumarate hydratase (Clark et al. 2014), and mutations of TMEM127 (Qin et al. 2014, Hernandez et al. 2015). A new syndrome of paraganglioma and duodenal somatostatinoma associated with polycythemia

Published by Bioscientifica Ltd. 
has been reported in patients with mutations of HIF2A (Pacak et al. 2013). Both pathologists and clinicians must be aware that combinations of tumors in patients or families with pheochromocytoma or paraganglioma might not be coincidental. However, coincidence must also be considered, particularly if one of the tumors is a common one such as a pituitary adenoma or papillary thyroid carcinoma, which has also been reported in some patients with SDHx mutations (Neumann et al. 2004, Papathomas et al. 2014). A further consideration is that syndromic tumors often do not present synchronously, and the first manifestation of a pheochromocytoma/ paraganglioma syndrome might not be a pheochromocytoma or paraganglioma.

In order to deal with the new complexity, pathologists must first be aware that a variety of tumors are now associated with hereditary pheochromocytoma and paraganglioma and that these tumors can occur in unexpected combinations. Second, they must be familiar with nuances of each type of tumor. For example, GISTs associated with loss of function of succinate dehydrogenase, whether caused by germline mutations or by other mechanisms such as methylation in Carney Triad (Haller et al. 2014), almost always are located in the stomach, usually have epithelioid morphology, and tend to occur in children or young adults (Miettinen et al. 2011). In contrast, sporadic GISTs and those associated with NF1 mutation have spindle cell or epithelioid morphology and occur anywhere in the GI tract (Agaimy et al. 2012). Similarly, succinate dehydrogenase related renal cell carcinomas, which are most often associated with $S D H B$ or $S D H D$ mutations, have characteristic features including cuboidal cells arranged in solid nests surrounding tubules or cystic spaces, with bubbly cytoplasm, indistinct borders, and vacuolated cytoplasmic inclusions corresponding to giant mitochondria (Gill et al. 2011a). In contrast, renal carcinomas associated with VHL mutations are usually conventional clear cell carcinomas, while other types of hereditary renal cell carcinomas have their own characteristic features (Gill et al. 2011a). Collectively, $\sim 4 \%$ of renal cell carcinomas (Gill et al. 2011a) and a comparable percentage of GISTs are hereditary.

In addition to morphology, an important tool that pathologists have at their disposal in screening for inherited disease is immunohistochemistry. In a study of a small number of cases in 2005, Dahia et al. were first to show by immunohistochemistry and immunoblots that SDHB protein expression is lost in hereditary paraganglioma with $S D H B$ or $S D H D$ mutations (Dahia et al. 2005). Subsequent large series showed that this occurs in hereditary tumors harboring loss-of-function germline mutations in any of the genes that separately encode components of the functional succinate dehydrogenase complex: $S D H A, S D H B, S D H C$, SDHD, and SDHAF2 (van Nederveen et al. 2009, Burnichon et al. 2010, Papathomas et al. 2015). The loss of immunoreactivity in tumor cells typically occurs after loss or inactivation of the WT allele, while endothelial cells in the same tumor, which have not lost the WT allele, serve as positively stained controls. Such positive staining typically is granular staining of varying intensity. Negative or weak non-granular staining of tumor cells therefore strongly suggests that loss of succinate dehydrogenase activity is causally related to tumor development (Fig. 3).

Immunohistochemistry for SDHB can serve as both a screening procedure to triage patients who present with a pheochromocytoma or paraganglioma for genetic testing and as an indicator of whether other tumors in those patients are legitimate components of an $S D H x$-related syndrome or incidental findings. It has been shown that interobserver variability of this type of immunohistochemistry is relatively good, but familiarity and experience with the specific staining patterns are needed. Loss of immunoreactivity has also been confirmed in GISTs (Gill et al. 2011b), renal cell carcinomas (Gill et al. 2011a), and a subset of pituitary adenomas (Papathomas et al. 2014, Xekouki et al. 2015) in pheochromocytoma/ paraganglioma patients, as well as in subsets of GISTs and RCCs arising de novo. It has been recommended that all RCCs with unusual morphology or a family history of RCC be stained for SDHB (Gill et al. 2011a).

It is of interest that although SDHB protein is lost with mutations of any of the $S D H x$ genes, immunoreactivity for SDHA is lost only when there are mutations of SDHA, providing a more focused immunohistochemical screening tool (Korpershoek et al. 2011). Serendipitously, a new SDHD antibody has been found to stain only tumors that do have SDHD mutations and might be helpful because those tumors sometimes retain weak background staining for SDHB (Menara et al. 2015). It is likely that additional antibodies will become available in the future.

At the same time that immunohistochemistry is proving its worth in evaluation of patients with hereditary pheochromocytoma/paraganglioma, declining costs of next-generation sequencing (NGS) to screen for mutations of multiple susceptibility genes are likely to make this technology available to increasing numbers of patients and to reduce the need for primary immunohistochemical triage (Welander et al. 2014). Nonetheless, immunohistochemistry will likely continue to play a role in validating

Published by Bioscientifica Ltd. 

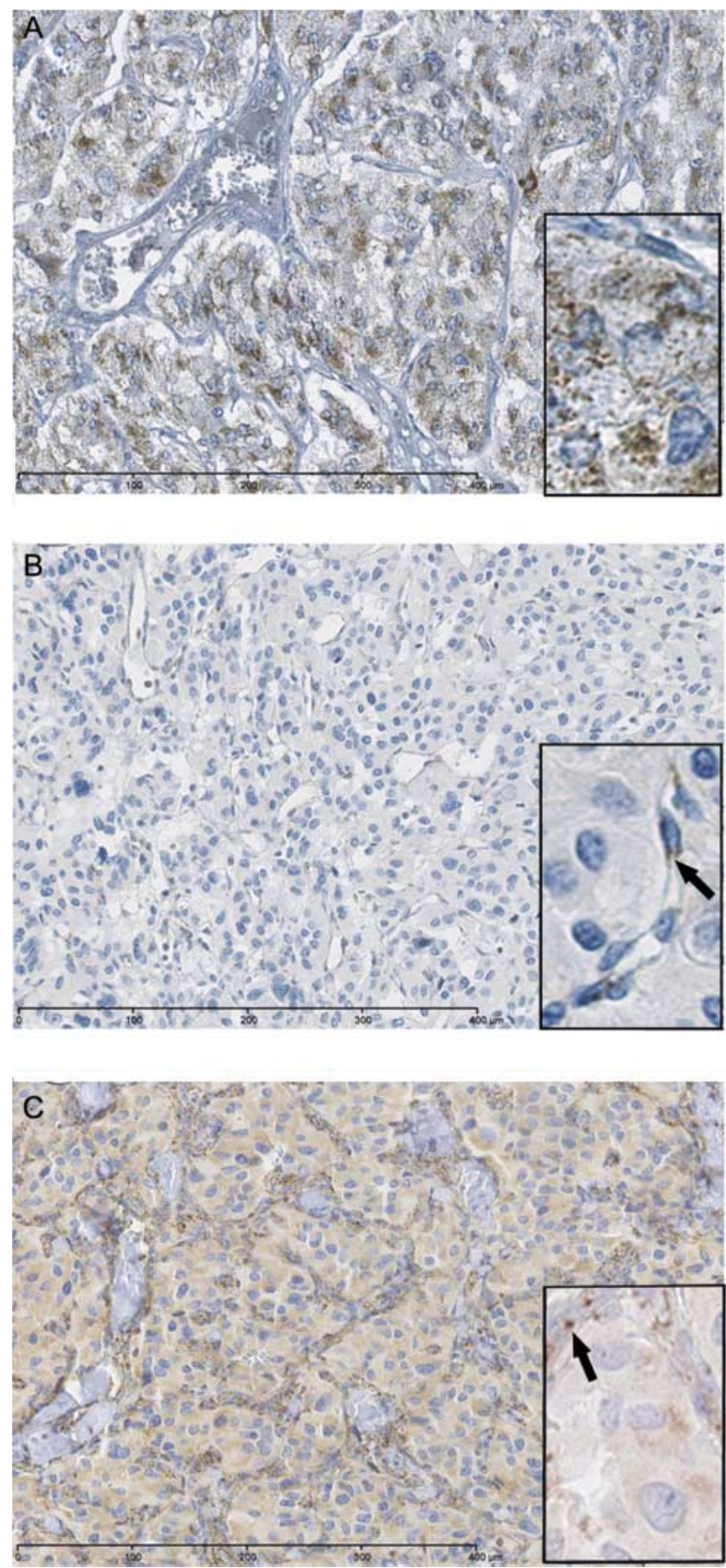

Figure 3

Patterns of immunohistochemical staining for SDHB. (A) Positive staining consistent with WT SDHx genes. The granular pattern corresponds to the mitochondrial localization of the SDH complex. (B) Negative staining of tumor cells, with positive staining of endothelial cells in small vessels serving as an intrinsic control (arrow); (C) SDHD-mutated extra-adrenal PGL that shows weak diffuse (background) staining of the tumor cells and positive granular staining of the endothelial cells (arrow). In order to be interpreted as positive, tumor cell staining should have a granular pattern and be as intense as the staining of endothelial cells. (Original artwork by Dr Esther Korpershoek). variants of uncertain significance (VUS) detected by NGS. The foundation for this use of immunohistochemistry is already partly established for SDHx-associated tumors (Papathomas et al. 2015), although an updated SDHx database (Bayley et al. 2005) containing all relevant mutations with accompanying data including immunohistochemistry is needed. Applicability to tumors associated with mutations of other genes such as MAX (Comino-Mendez et al. 2011) may be limited by inadequate commercially available antibodies, the existence of immunoreactive but nonfunctional proteins, and other factors.

\section{Risk stratification and diagnosis of 'malignancy'}

There are currently no validated, generally accepted pathology criteria for determining whether a primary PC or PG is benign or malignant. Although a few studies starting in the 1980s did attempt to identify distinctive tumor characteristics associated with malignancy, early efforts were impeded by inconsistent nomenclature. Extraadrenal sympathetic paragangliomas were often classified as pheochromocytomas, causing tumor location, which is an important predictor of risk, to be obscured in some papers. There were also conflicting definitions of 'malignancy' itself, which could mean either local invasion or metastasis. These problems were partially solved by the 2004 WHO classification (DeLellis et al. 2004), which defines malignancy by the development of metastases and not by local invasion. This can be justified by the fact that local invasion by itself is not a good predictor of metastases, but it does not adequately deal with the fact that local invasion, while not officially malignant, can still be fatal. To avoid confusing multiple primary tumors with metastases, the definition further specifies that metastases should be to sites where normal paraganglia do not occur, which would include bone, liver, and histologically confirmed lymph nodes. Lung is also a common site of metastasis, but it should be kept in mind that primary paragangliomas probably do rarely occur in lung (Aubertine \& Flieder 2004). Although the adrenal medulla is a paraganglion and a pheochromocytoma is therefore an intra-adrenal paraganglioma, an additional convention codified in WHO 2004 restricted the term 'pheochromocytoma' to tumors of the adrenal medulla while calling their closely related counterparts in other sites paragangliomas. This distinction was completely arbitrary. Its origin can be traced to 1950 in the first series of the Armed Forces Institute of Pathology tumor

Published by Bioscientifica Ltd 
atlases where H T Karsner, writing in Tumors of the Adrenal, commented on confusion caused by head and neck paragangliomas and even carcinoid tumors being diagnosed as pheochromocytomas and suggested that 'an agreement in nomenclature, even on an arbitrary basis, is helpful' (Karsner 1950, reviewed in Tischler (2008a)). The standardized terminology has mostly served its purpose.

Many papers published by pathologists have reported morphological, immunohistochemical, and other features correlated with metastatic potential of pheochromocytomas or paragangliomas. Some have withstood the test of time while others remain controversial or unconfirmed, or have shown insufficient concordance between pathologists to be of practical use (Favier et al. 2002, Oudijk et al. 2015a). No individual findings have been sufficiently reliable to allow a tumor to be confidently dismissed as benign. Attempts have therefore been made to develop multiparameter scoring systems for risk stratification. A seminal study of pheochromocytomas and sympathetic paragangliomas by Linnoila et al. (1990) identified extraadrenal location, confluent necrosis, coarse nodularity, and absence of hyaline globules as adverse features. Of these, the most powerful independent predictive value was for extra-adrenal location (Linnoila et al. 1990), which is now known to correlate with $S D H B$ mutation (Eisenhofer et al. 2012). Two subsequently developed scoring systems are the Pheochromocytoma of the Adrenal Scaled Score (PASS), proposed by Thompson (2002), and the Grading system for Adrenal Phaeochromocytoma and Paraganglioma (GAPP), proposed by Kimura et al. (2014) (Fig. 4). While PASS applies only to pheochromocytomas, GAPP applies to both pheochromocytomas and paragangliomas. Morphological features scored in PASS or GAPP are illustrated in Fig. 5.

As shown in Fig. 4, several features are common to PASS and GAPP. These include tumor necrosis, which was also scored by Linnoila et al. and is seen in a variety of malignant tumors. Similarly, 'high cellularity' is a reflection of small cell size, consistent with the observation by Medeiros et al. (1985) that pheochromocytomas most likely to metastasize were composed of relatively small cells. Although these recurrent themes might carry some implied validity, several problems still prevent either system from being generally accepted or officially endorsed. Of greatest immediacy, the PASS was found to have very poor concordance between expert endocrine pathologists in a validation study ( $\mathrm{Wu}$ et al. 2009). This might have contributed to some
PASS*

*Pheochromocytoma of the Adrenal Scaled Score (Thompson, 2002)

\begin{tabular}{|c|c|}
\hline Feature & $\begin{array}{l}\text { Score if present } \\
\text { (no. of points assigned) }\end{array}$ \\
\hline $\begin{array}{l}\text { Large nests or diffuse growth } \\
\text { (>10\% of tumor volume) }\end{array}$ & 2 \\
\hline $\begin{array}{l}\text { Central (middle of large nests) } \\
\text { or confluent tumor necrosis } \\
\text { (not degenerative change) }\end{array}$ & 2 \\
\hline High cellularity & 2 \\
\hline Cellular monotony & 2 \\
\hline Tumor cell spindling (even if focal) & 2 \\
\hline Mitotic figures $>3 / 10 \mathrm{HPF}$ & 2 \\
\hline Atypical mitotic figure(s) & 2 \\
\hline Extension into adipose tissue & 2 \\
\hline Vascular invasion & 1 \\
\hline \begin{tabular}{l|l} 
Capsular invasion &
\end{tabular} & 1 \\
\hline Profound nuclear pleomorphism & 1 \\
\hline Nuclear hyperchromasia & 1 \\
\hline Total & 20 \\
\hline
\end{tabular}

\section{Figure 4}

Comparison of the PASS and GAPP scoring systems. The superimposed colored boxes show overlapping parameters. Note the different weighting of the important parameters of vascular and capsular invasion.

(I) Republished with permission of Lippincott Williams \& Wilkins, Inc., from Pheochromocytoma of the adrenal gland scaled score (PASS) to separate benign from malignant neoplasms: a clinicopathologic and immunophenotypic study of 100 cases, Thompson LD, American Journal of Surgical

\section{GAPP ** $^{*}$}

${ }^{* *}$ Grading of Adrenal Pheochromocytoma and Paraganglioma (Kimura 2014)

\begin{tabular}{|c|c|}
\hline Parameters & Points scored \\
\hline \multicolumn{2}{|l|}{ Histological pattern } \\
\hline Zellballen & 0 \\
\hline Large and irregular cell nest & 1 \\
\hline Pseudorosette (even focal) & 1 \\
\hline \multicolumn{2}{|l|}{ Cellularity } \\
\hline Low (<150 cells/U) & 0 \\
\hline Moderate $(150-250$ cells/U) & 1 \\
\hline High (more than 250 cells/U) & 2 \\
\hline \multicolumn{2}{|l|}{ Comedo necrosis } \\
\hline Absence & 0 \\
\hline Presence & 2 \\
\hline \multicolumn{2}{|l|}{ Vascular or capsular invasion } \\
\hline Absence & 0 \\
\hline Presence & 1 \\
\hline \multicolumn{2}{|l|}{ Ki67 labelling index (\%) } \\
\hline$<1$ & 0 \\
\hline $1-3$ & 1 \\
\hline$>3$ & 2 \\
\hline \multicolumn{2}{|l|}{ Catecholamine type } \\
\hline Epinephrine type (E or E+NE) & 0 \\
\hline Norepinephrine type (NE or NE+DA) & 1 \\
\hline Non-functioning type & 0 \\
\hline Total maximum score & 10 \\
\hline
\end{tabular}

Pathology, volume 26, pp551-566, copyright 2002; permission conveyed through Copyright Clearance Center, Inc. ( $r$ ) Reproduced, with permission, from Kimura N, Takayanagi R, Takizawa N, Itagaki E, Katabami T, Kakoi N, Rakugi H, Ikeda Y, Tanabe A, Nigawara T, et al. (2014) Pathological grading for predicting metastasis in phaeochromocytoma and paraganglioma. Endocrine-Related Cancer 21 405-414. Published under the terms of the CCBY licence.

Published by Bioscientifica Ltd. 

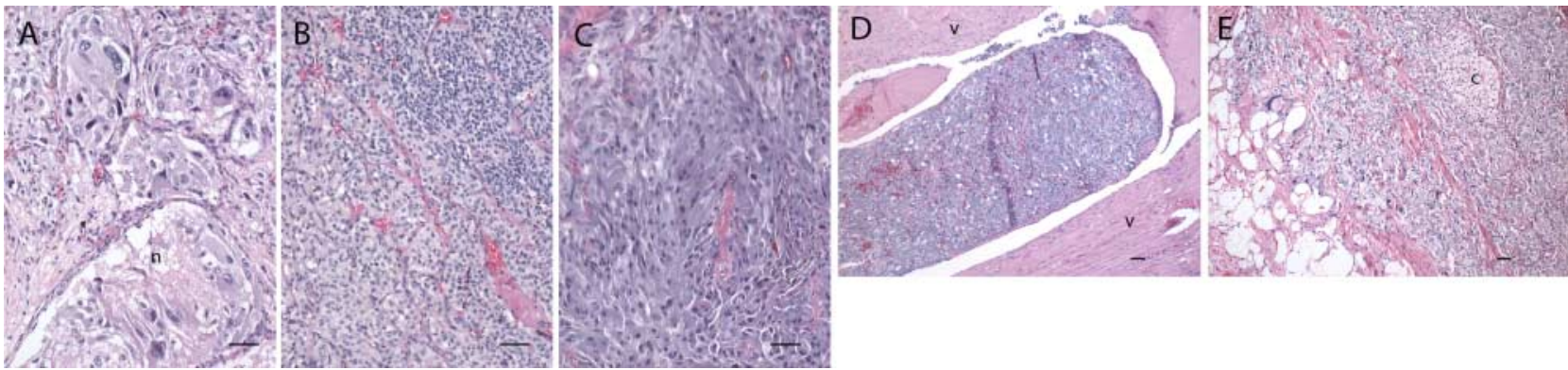

\section{Figure 5}

Putative adverse histological features in the PASS and/or GAPP scoring systems. (A) irregular Zellballen, necrosis ( $n$ ) and extreme atypia; (B) high cellularity (at top right); (C) spindle cells; (D) vascular invasion, with tumor in adrenal vein ( $v$ indicates vein walls); $(E)$ invasion of periadrenal fat (c indicates residual adrenal cortex). Bars $=50 \mu \mathrm{m}$. The tumors shown in all

pathologists having found it useful and others not. While GAPP removed some of the poorly concordant features in PASS, GAPP has so far had no validation study, although one is currently in the planning stage. There are also several intrinsic problems with GAPP in its present form, as recently reviewed (Eisenhofer \& Tischler 2014). While the final GAPP grade combines points for histological features and biochemical phenotype and is therefore not a conventional pathology grade, it fails to account for other nonhistological features that are established risk factors, including tumor size and location, or for the influence of location on biochemical phenotype. There are also inconsistencies in the way biochemical phenotype is assessed (Eisenhofer \& Tischler 2014). The most important consideration for both PASS and GAPP is that tumor genotypes were not accounted for when the systems were developed, and the scored parameters might have different significance depending on genetic context. For example, spindle cells, which are adverse features in both systems, are common in pheochromocytomas associated with MEN2A, which rarely if ever metastasize (Fig. 5C). Further, it must be remembered that $\sim 4 \%$ of tumors with low GAPP scores did metastasize (Kimura et al. 2014), and that surveillance can therefore not be totally discontinued even for patients whose tumors have low GAPP scores. Most of the adverse GAPP features can be absent in metastases from low-scoring tumors as well as in the primary tumors (Fig. 6).

Immunohistochemistry has been utilized in several ways to test for markers of malignancy. Early studies staining for $\mathrm{S} 100$ protein demonstrated reduced numbers of sustentacular cells in aggressive tumors (Lloyd et al. 1985), but the finding is not consistent (Unger et al. 1991). Further, sustentacular cells can be either absent or present panels are pheochromocytomas except for $B$, which is a carotid body paraganglioma. $C$ and $E$ are from patients with MEN2A and have not recurred after 3 years and 28 years of follow-up, respectively. B and D are apparently sporadic tumors with only short-term follow-up. The patient whose tumor is panel A was lost to follow-up.

in metastases (Unger et al. 1991), adding to the uncertainty of whether or not they are neoplastic. The proliferation marker Ki67 historically yielded wildly varied results, in part because of inconsistent scoring methods (Tischler 2008a). The GAPP system now scores Ki67 using the same 'hotspot' counting approach applied to gastrointestinal and pancreatic neuroendocrine tumors. This standardization is probably an improvement, although different methods have not been evaluated side by side for pheochromocytoma/paraganglioma. Many other types of markers involved in cellular functions, including angiogenesis, cell adhesion, cell cycle control, telomere extension, and epithelial-mesenchymal transition, have also been tested, with mixed results (Eisenhofer et al. 2012).

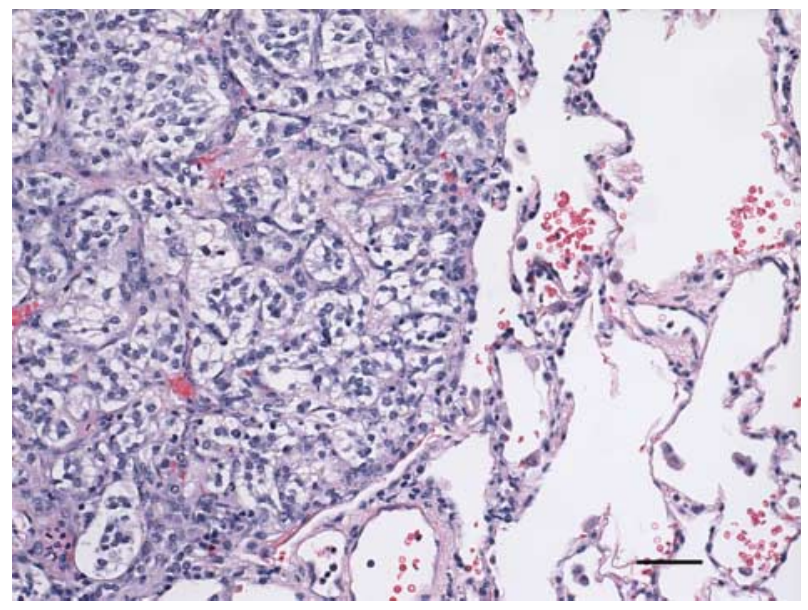

Figure 6

A pulmonary metastasis from a jugulotympanic paraganglioma. Aside from irregular Zellballen, this metastasis lacks the adverse features shown in Fig. 5. Bar $=50 \mu \mathrm{m}$.

Published by Bioscientifica Ltd. 
Many of the reported immunohistochemical studies of pheochromocytoma/paraganglioma are similar to purely morphological ones in lacking information about tumor genotype. However, this information is available in a recent paper reporting that 11 tumor stem cell markers were exclusively expressed in tumors with $S D H B$ mutations (Oudijk et al. 2015b). This is likely to be the case for other immunohistochemical markers as well. Since it is already established that metastatic potential is strongly correlated with $S D H B$ mutation, the independent predictive value of genetic testing probably outweighs the current value of immunohistochemistry in many cases, and the most predictive immunohistochemistry test is probably staining for SDHB.

In 2015, pathologists are frequently still asked by clinicians and tumor registries whether a primary pheochromocytoma or paraganglioma is malignant, despite the absence of established criteria for making that distinction. The question becomes particularly confused if a tumor is extensively invasive. A possible solution to this problem would be to eliminate the term 'malignant' (Tischler $2008 b$ ) and replace it with a diagnostic classification based on multi-parameter risk stratification (Eisenhofer et al. 2012). A precedent for this type of approach has already been set for low-grade neuroendocrine tumors of the gastro-entero-pancreatic axis (Klöppel 2011), which have many similarities to pheochromocytoma/paraganglioma and are currently all considered to have the potential to metastasize (Pasaoglu et al. 2015).

\section{Pathology reporting}

Many surgeries for pheochromocytoma and paraganglioma are not performed in specialized centers, and many clinicians are not familiar with the complexities of this group of tumors. There is therefore a need for a reporting format that both documents essential information about a specific specimen and conveys the broader implications of the findings. In the United States, cancer reporting protocols published by the College of American Pathologists were adopted in 2004 by the American College of Surgeons Commission on Cancer as the standard for required data elements. As of the January 2015 release on the CAP website (www.CAP.org), there was no protocol for pheochromocytoma or paraganglioma. A comprehensive reporting template proposed by Mete et al. (2014a) contained a novel section on clinicopathologic correlation but was not adopted by the CAP due to the current lack of outcome-based evidence for many of the proposed reporting elements (Washington et al. 2014), including elements contained in the GAPP and PASS systems. It therefore rests on pathologists to reach a consensus on reporting. This consensus will have to be based on international collaborative studies such as the one currently being planned for validation of the GAPP system.

\section{Declaration of interests}

The authors declare that there is no conflict of interest that could be perceived as prejudicing the impartiality of this review.

\section{Funding}

This review did not receive any specific grant from any funding agency in the public, commercial or not-for-profit sector.

\section{References}

Agaimy A, Vassos N \& Croner RS 2012 Gastrointestinal manifestations of neurofibromatosis type 1 (Recklinghausen's disease): clinicopathological spectrum with pathogenetic considerations. International Journal of Clinical and Experimental Pathology 5 852-862.

Aubertine CL \& Flieder DB 2004 Primary paraganglioma of the lung. Annals of Diagnostic Pathology 8 237-241. (doi:10.1053/j.anndiagpath. 2004.04.008)

Bayley JP, Devilee P \& Taschner PE 2005 The SDH mutation database: an online resource for succinate dehydrogenase sequence variants involved in pheochromocytoma, paraganglioma and mitochondrial complex II deficiency. BMC Medical Genetics 6 39. (doi:10.1186/1471-2350-6-39)

Bausch B, Borozdin W, Neumann HP \& European-American Pheochromocytoma Study Group 2006 Clinical and genetic characteristics of patients with neurofibromatosis type 1 and pheochromocytoma. New England Journal of Medicine 354 2729-2731. (doi:10.1056/ NEJMc066006)

Baysal BE, Ferrell RE, Willett-Brozick JE, Lawrence EC, Myssiorek D, Bosch A, van der Mey A, Taschner PE, Rubinstein WS, Myers EN et al. 2000 Mutations in SDHD, a mitochondrial complex II gene, in hereditary paraganglioma. Science $\mathbf{2 8 7}$ 848-851. (doi:10.1126/science. 287.5454.848)

Bellezza G, Giansanti M, Cavaliere A \& Sidoni A 2004 Pigmented "black" pheochromocytoma of the adrenal gland: a case report and review of the literature. Archives of Pathology \& Laboratory Medicine 128 e125-e128.

Burke AP \& Helwig EB 1989 Gangliocytic paraganglioma. American Journal of Clinical Pathology 92 1-9.

Burnichon N, Briere JJ, Libe R, Vescovo L, Riviere J, Tissier F, Jouanno E, Jeunemaitre X, Benit P, Tzagoloff A et al. 2010 SDHA is a tumor suppressor gene causing paraganglioma. Human Molecular Genetics 19 3011-3020. (doi:10.1093/hmg/ddq206)

Chetty R, Pillay P \& Jaichand V 1998 Cytokeratin expression in adrenal phaeochromocytomas and extra-adrenal paragangliomas. Journal of Clinical Pathology 51 477-478. (doi:10.1136/jcp.51.6.477)

Clark GR, Sciacovelli M, Gaude E, Walsh DM, Kirby G, Simpson MA, Trembath RC, Berg JN, Woodward ER, Kinning E et al. 2014 Germline FH mutations presenting with pheochromocytoma. Journal of Clinical Endocrinology and Metabolism 99 E2046-E2050. (doi:10.1210/jc. 2014-1659)

Comino-Mendez I, Gracia-Aznarez FJ, Schiavi F, Landa I, Leandro-Garcia LJ, Leton R, Honrado E, Ramos-Medina R, Caronia D, Pita G et al. 2011 Exome sequencing identifies MAX mutations as a cause of hereditary pheochromocytoma. Nature Genetics 43 663-667. (doi:10.1038/ng.861)

Published by Bioscientifica Ltd. 
Dahia PL 2013 The genetic landscape of pheochromocytomas and paragangliomas: somatic mutations take center stage. Journal of Clinical Endocrinology and Metabolism 98 2679-2681. (doi:10.1210/jc.2013-2191)

Dahia PL, Ross KN, Wright ME, Hayashida CY, Santagata S, Barontini M, Kung AL, Sanso G, Powers JF, Tischler AS et al. 2005 A HIF1 $\alpha$ regulatory loop links hypoxia and mitochondrial signals in pheochromocytomas. PLoS Genetics 1 e8. (doi:10.1371/journal.pgen.0010008)

DeLellis RA, Lloyd RV, Heitz PU \& Eng C (Eds) 2004 World Health Organization Classification of Tumours: Pathology and Genetics of Tumours of Endocrine Organs. Lyon, France: IARC Press.

Diaz-Cano SJ, de Miguel M, Blanes A, Tashjian R, Galera H \& Wolfe HJ 2000 Clonal patterns in phaeochromocytomas and MEN-2A adrenal medullary hyperplasias: histological and kinetic correlates. Journal of Pathology 192 221-228. (doi:10.1002/1096-9896(2000)9999:9999 $<:$ AID-PATH679>3.0.CO;2-B)

von Dobschuetz E, Leijon H, Schalin-Jantti C, Schiavi F, Brauckhoff M, Peczkowska M, Spiazzi G, Dematte S, Cecchini ME, Sartorato P et al. 2015 A registry-based study of thyroid paraganglioma: histological and genetic characteristics. Endocrine-Related Cancer 22 191-204. (doi:10.1530/ERC-14-0558)

Douwes Dekker PB, Corver WE, Hogendoorn PC, van der Mey AG \& Cornelisse CJ 2004 Multiparameter DNA flow-sorting demonstrates diploidy and SDHD wild-type gene retention in the sustentacular cell compartment of head and neck paragangliomas: chief cells are the only neoplastic component. Journal of Pathology 202 456-462. (doi:10.1002/ path.1535)

Eisenhofer G \& Tischler AS 2014 Neuroendocrine cancer. Closing the GAPP on predicting metastases. Nature Reviews. Endocrinology 10 315-316. (doi:10.1038/nrendo.2014.41)

Eisenhofer G, Tischler AS \& de Krijger RR 2012 Diagnostic tests and biomarkers for pheochromocytoma and extra-adrenal paraganglioma: from routine laboratory methods to disease stratification. Endocrine Pathology 23 4-14. (doi:10.1007/s12022-011-9188-1)

Favier J, Plouin PF, Corvol P \& Gasc JM 2002 Angiogenesis and vascular architecture in pheochromocytomas: distinctive traits in malignant tumors. American Journal of Pathology 161 1235-1246. (doi:10.1016/ S0002-9440(10)64400-8)

Favier J, Amar L \& Gimenez-Roqueplo AP 2015 Paraganglioma and phaeochromocytoma: from genetics to personalized medicine. Nature Reviews. Endocrinology 11 101-111. (doi:10.1038/nrendo.2014.188)

Gill AJ, Pachter NS, Chou A, Young B, Clarkson A, Tucker KM, Winship IM, Earls P, Benn DE, Robinson BG et al. 2011a Renal tumors associated with germline SDHB mutation show distinctive morphology. American Journal of Surgical Pathology 35 1578-1585. (doi:10.1097/PAS. Ob013e318227e7f4)

Gill AJ, Chou A, Vilain R, Clarkson A, Lui M, Jin R, Tobias V, Samra J, Goldstein D, Smith C et al. 2011 Immunohistochemistry for SDHB divides gastrointestinal stromal tumors (GISTs) into 2 distinct types. American Journal of Surgical Pathology 34 636-644. (doi:10.1097/PAS. Ob013e3181d6150d)

Gosney JR, Denley H \& Resl M 1999 Sustentacular cells in pulmonary neuroendocrine tumours. Histopathology 34 211-215. (doi:10.1046/ j.1365-2559.1999.00595.x)

Haller F, Moskalev EA, Faucz FR, Barthelmess S, Wiemann S, Bieg M, Assie G, Bertherat J, Schaefer IM, Otto C et al. 2014 Aberrant DNA hypermethylation of SDHC: a novel mechanism of tumor development in Carney triad. Endocrine-Related Cancer 21 567-577. (doi:10.1530/ ERC-14-0254)

Hernandez KG, Ezzat S, Morel CF, Swallow C, Otremba M, Dickson BC, Asa SL \& Mete O 2015 Familial pheochromocytoma and renal cell carcinoma syndrome: TMEM127 as a novel candidate gene for the association. Virchows Archiv 466 727-732. (doi:10.1007/s00428015-1755-2)

Johnson TL, Zarbo RJ, Lloyd RV \& Crissman JD 1988 Paragangliomas of the head and neck: immunohistochemical neuroendocrine and intermediate filament typing. Modern Pathology 1 216-223.
Karsner HT 1950 Tumors of the Adrenal. Atlas of Tumor Pathology, Section VIII-Fascicle 29. Washington, DC, USA: Armed Forces Institute of Pathology. Kimura N, Takayanagi R, Takizawa N, Itagaki E, Katabami T, Kakoi N, Rakugi H, Ikeda Y, Tanabe A, Nigawara T et al. 2014 Pathological grading for predicting metastasis in phaeochromocytoma and paraganglioma. Endocrine-Related Cancer 21 405-414. (doi:10.1530/ ERC-13-0530)

Klöppel G 2011 Classification and pathology of gastroenteropancreatic neuroendocrine neoplasms. Endocrine-Related Cancer 18 S1-S16. (doi:10.1530/ERC-11-0013)

Koch CA, Mauro D, Walther MM, Linehan WM, Vortmeyer AO, Jaffe R, Pacak K, Chrousos GP, Zhuang Z \& Lubensky IA 2002 Pheochromocytoma in von hippel-lindau disease: distinct histopathologic phenotype compared to pheochromocytoma in multiple endocrine neoplasia type 2. Endocrine Pathology 13 17-27. (doi:10.1385/EP:13:1:17)

Korpershoek E, Favier J, Gaal J, Burnichon N, van Gessel B, Oudijk L, Badoual C, Gadessaud N, Venisse A, Bayley JP et al. 2011 SDHA immunohistochemistry detects germline SDHA gene mutations in apparently sporadic paragangliomas and pheochromocytomas. Journal of Clinical Endocrinology and Metabolism 96 E1472-E1476. (doi:10.1210/jc.2011-1043)

Korpershoek E, Petri B-J, Post E, van Eijck CH, Oldenburg RA, Belt EJ, de Herder WW, de Krijger RR \& Dinjens WN 2014 Adrenal medullary hyperplasia is a precursor lesion for pheochromocytoma in MEN2 syndrome. Neoplasia 16 868-873. (doi:10.1016/j.neo.2014.09.002)

Labrousse F, Leboutet MJ, Petit B, Paraf F, Boncoeur-Martel MP, Moreau JJ \& Catanzano G 1999 Cytokeratins expression in paragangliomas of the cauda equina. Clinical Neuropathology 18 208-213.

Lenders JW, Duh QY, Eisenhofer G, Gimenez-Roqueplo AP, Grebe SK, Murad MH, Naruse M, Pacak K \& Young WF Jr 2014 Pheochromocytoma and paraganglioma: an Endocrine Society clinical practice guideline. Journal of Clinical Endocrinology and Metabolism 99 1915-1942. (doi:10.1210/jc.2014-1498). (letter: http://press.endocrine. org/e-letters/10.1210/jc.2014-1498)

Linnoila RI, Keiser HR, Steinberg SM \& Lack EE 1990 Histopathology of benign versus malignant sympathoadrenal paragangliomas: clinicopathologic study of 120 cases including unusual histologic features (see comments). Human Pathology 21 1168-1180. (doi:10.1016/00468177(90)90155-X)

Lloyd RV, Blaivas M \& Wilson BS 1985 Distribution of chromogranin and S100 protein in normal and abnormal adrenal medullary tissues. Archives of Pathology \& Laboratory Medicine 109 633-635.

Medeiros LJ, Wolf BC, Balogh K \& Federman M 1985 Adrenal pheochromocytoma: a clinicopathologic review of 60 cases. Human Pathology 16 580-589. (doi:10.1016/S0046-8177(85)80107-6)

Menara M, Oudijk L, Badoual C, Bertherat J, Lepoutre-Lussey C, Amar L, Iturrioz X, Sibony M, Zinzindohoue F, de Krijger R et al. 2015 SDHD immunohistochemistry: a new tool to validate SDHx mutations in pheochromocytoma/paraganglioma. Journal of Clinical Endocrinology and Metabolism 100 E287-E291. (doi:10.1210/jc.2014-1870)

Mete O, Tischler AS, de Krijger R, McNicol AM, Eisenhofer G, Pacak K, Ezzat S \& Asa SL 2014a Protocol for the examination of specimens from patients with pheochromocytomas and extra-adrenal paragangliomas. Archives of Pathology \& Laboratory Medicine 138 182-188. (doi:10.5858/ arpa.2012-0551-OA)

Mete O, Tischler AS, de Krijger R, McNicol AM, Giordano T, Ezzat S \& Asa SL $2014 b$ Letter to the Editor: The clinical role of pathologists in the management of patients with paragangliomas and pheochromocytomas. Journal of Clinical Endocrinology and Metabolism 99 eletter. (available at: http://press.endocrine.org/e-letters/10.1210/jc.2014-1498)

Miettinen M, Wang ZF, Sarlomo-Rikala M, Osuch C, Rutkowski P \& Lasota J 2011 Succinate dehydrogenase-deficient GISTs: a clinicopathologic, immunohistochemical, and molecular genetic study of 66 gastric GISTs with predilection to young age. American Journal of Surgical Pathology 35 1712-1721. (doi:10.1097/PAS. Ob013e3182260752) 
van Nederveen FH, Korpershoek E, deLeeuw RJ, Verhofstad AA, Lenders JW, Dinjens WN, Lam WL \& de Krijger RR 2009 Array-comparative genomic hybridization in sporadic benign pheochromocytomas. EndocrineRelated Cancer 16 505-513. (doi:10.1677/ERC-08-0241)

Neumann HP, Berger DP, Sigmund G, Blum U, Schmidt D, Parmer RJ, Volk B \& Kirste G 1993 Pheochromocytomas, multiple endocrine neoplasia type 2, and von Hippel-Lindau disease. New England Journal of Medicine 329 1531-1538. (doi:10.1056/NEJM199311183292103)

Neumann HP, Bausch B, McWhinney SR, Bender BU, Gimm O, Franke G, Schipper J, Klisch J, Altehoefer C, Zerres K et al. 2002 Germ-line mutations in nonsyndromic pheochromocytoma. New England Journal of Medicine 346 1459-1466. (doi:10.1056/NEJMoa020152)

Neumann HP, Pawlu C, Peczkowska M, Bausch B, McWhinney SR, Muresan M, Buchta M, Franke G, Klisch J, Bley TA et al. 2004 Distinct clinical features of paraganglioma syndromes associated with SDHB and SDHD gene mutations. Journal of the American Medical Association 292 943-951. (doi:10.1001/jama.292.8.943)

Oudijk L, van Nederveen F, Badoual C, Tissier F, Tischler AS, Smid M, Gaal J, Lepoutre-Lussey C, Gimenez-Roqueplo AP, Dinjens WN et al. $2015 a$ Vascular pattern analysis for the prediction of clinical behaviour in pheochromocytomas and paragangliomas. PLOS ONE 10 e0121361. (doi:10.1371/journal.pone.0121361)

Oudijk L, Neuhofer CM, Lichtenauer UD, Papathomas TG, Korpershoek E, Stoop H, Oosterhuis JW, Smid M, Restuccia DF, Robledo M et al. 2015b Immunohistochemical expression of stem cell markers in pheochromocytoma/paraganglioma is associated with SDHx-mutations. European Journal of Endocrinology/European Federation of Endocrine Societies 173 43-52. (doi:10.1530/EJE-14-1164)

Pacak K \& Wimalawansa SJ 2015 Pheochromocytoma and paraganglioma. Endocrine Practice 21 406-412. (doi:10.4158/EP14481.RA)

Pacak K, Jochmanova I, Prodanov T, Yang C, Merino MJ, Fojo T, Prchal JT, Tischler AS, Lechan RM \& Zhuang Z 2013 New syndrome of paraganglioma and somatostatinoma associated with polycythemia. Journal of Clinical Oncology 31 1690-1698. (doi:10.1200/JCO.2012.47.1912)

Papathomas TG, Gaal J, Corssmit EP, Oudijk L, Korpershoek E, Heimdal K, Bayley JP, Morreau H, van Dooren M, Papaspyrou K et al. 2014 Nonpheochromocytoma (PCC)/paraganglioma (PGL) tumors in patients with succinate dehydrogenase-related PCC-PGL syndromes: a clinicopathological and molecular analysis. European Journal of Endocrinology/European Federation of Endocrine Societies 170 1-12. (doi:10.1530/EJE-13-0623)

Papathomas TG, Oudijk L, Persu A, Gill AJ, van Nederveen F, Tischler AS Tissier F, Volante M, Matias-Guiu X, Smid M et al. 2015 SDHB/SDHA immunohistochemistry in pheochromocytomas and paragangliomas: a multicenter interobserver variation analysis using virtual microscopy: a Multinational Study of the European Network for the Study of Adrenal Tumors (ENS@T). Modern Pathology 28 807-821. (doi:10.1038/ modpathol.2015.41)

Pasaoglu E, Dursun N, Ozyalvacli G, Hacihasanoglu E, Behzatoglu K \& Calay O 2015 Comparison of World Health Organization 2000/2004 and World Health Organization 2010 classifications for gastrointestinal and pancreatic neuroendocrine tumors. Annals of Diagnostic Pathology 19 81-87. (doi:10.1016/j.anndiagpath.2015.01.001)

Pasini B \& Stratakis CA 2009 SDH mutations in tumorigenesis and inherited endocrine tumours: lesson from the phaeochromocytomaparaganglioma syndromes. Journal of Internal Medicine 266 19-42. (doi:10.1111/j.1365-2796.2009.02111.x)

Qin Y, Deng Y, Ricketts CJ, Srikantan S, Wang E, Maher ER \& Dahia PL 2014 The tumor susceptibility gene TMEM127 is mutated in renal cell carcinomas and modulates endolysosomal function. Human Molecular Genetics 23 2428-2439. (doi:10.1093/hmg/ddt638)
Rubin de Celis MF, Garcia-Martin R, Wittig D, Valencia GD, Enikolopov G, Funk RH, Chavakis T, Bornstein SR, Androutsellis-Theotokis A \& Ehrhart-Bornstein M 2015 Multipotent glia-like stem cells mediate stress adaptation. Stem Cells 33 2037-2051. (doi:10.1002/stem.2002)

Sangoi AR \& McKenney JK 2010 A tissue microarray-based comparative analysis of novel and traditional immunohistochemical markers in the distinction between adrenal cortical lesions and pheochromocytoma. American Journal of Surgical Pathology 34 423-432. (doi:10.1097/PAS. 0b013e3181cfb506)

Schmid KW, Schroder S, Dockhorn-Dworniczak B, Kirchmair R, Totsch M, Bocker W \& Fischer-Colbrie R 1994 Immunohistochemical demonstration of chromogranin A, chromogranin B, and secretogranin II in extra-adrenal paragangliomas. Modern Pathology 7 347-353.

Schuldt M, Retamero JA, Tourne M \& Nogales FF 2015 Ovarian paraganglioma. International Journal of Surgical Pathology 23 130-133. (doi:10.1177/1066896914526779)

Teicher BA, Linehan WM \& Helman LJ 2012 Targeting cancer metabolism. Clinical Cancer Research 18 5537-5545. (doi:10.1158/1078-0432.CCR12-2587)

Thompson LD 2002 Pheochromocytoma of the Adrenal gland Scaled Score (PASS) to separate benign from malignant neoplasms: a clinicopathologic and immunophenotypic study of 100 cases. American Journal of Surgical Pathology 26 551-566. (doi:10.1097/00000478-200205000-00002)

Tischler AS 2000 Divergent differentiation in neuroendocrine tumors of the adrenal gland. Seminars in Diagnostic Pathology 17 120-126.

Tischler AS 2008a Pheochromocytoma and extra-adrenal paraganglioma: updates. Archives of Pathology \& Laboratory Medicine 132 1272-1284.

Tischler AS 2008b Pheochromocytoma: time to stamp out "malignancy"? Endocrine Pathology 19 207-208. (doi:10.1007/s12022-008-9047-x)

Tischler AS 2012 Paraganglia. In Histology for Pathologists, 4th edn, pp1277-1299. Ed SE Mills. Philadelphia, PA, USA: Lippincott Williams and Wilkins.

Toledo SP, Lourenco DM Jr, Sekiya T, Lucon AM, Baena ME, Castro CC, Bortolotto LA, Zerbini MC, Siqueira SA, Toledo RA et al. 2015 Penetrance and clinical features of pheochromocytoma in a sixgeneration family carrying a germline TMEM127 mutation. Journal of Clinical Endocrinology and Metabolism 100 E308-E318. (doi:10.1210/ jc.2014-2473)

Unger P, Hoffman K, Pertsemlidis D, Thung S, Wolfe D \& Kaneko M 1991 S100 protein-positive sustentacular cells in malignant and locally aggressive adrenal pheochromocytomas. Archives of Pathology \& Laboratory Medicine 115 484-487.

Washington M, Baker TP \& Simpson J 2014 Checklists, protocols and the "gold standard" approach. Archives of Pathology \& Laboratory Medicine 138 159-160. (doi:10.5858/arpa.2013-0519-ED)

Welander J, Andreasson A, Juhlin CC, Wiseman RW, Backdahl M, Hoog A, Larsson C, Gimm O \& Soderkvist P 2014 Rare germline mutations identified by targeted next-generation sequencing of susceptibility genes in pheochromocytoma and paraganglioma. Journal of Clinical Endocrinology and Metabolism 99 E1352-E1360. (doi:10.1210/ jc.2013-4375)

Wu D, Tischler AS, Lloyd RV, DeLellis RA, de Krijger R, van Nederveen F \& Nose V 2009 Observer variation in the application of the Pheochromocytoma of the Adrenal Gland Scaled Score. American Journal of Surgical Pathology 33 599-608. (doi:10.1097/PAS.0b013e318190d12e)

Xekouki P, Szarek E, Bullova P, Giubellino A, Quezado M, Mastroyannis SA, Mastorakos P, Wassif CA, Raygada M, Rentia N et al. 2015 Pituitary adenoma with paraganglioma/pheochromocytoma (3PAs) and succinate dehydrogenase defects in human and mice. Journal of Clinical Endocrinology and Metabolism 100 E710-E719. (doi:10.1210/ jc.2014-4297)

Received in final form 26 June 2015

Accepted 1 July 2015

Made available online as an Accepted Preprint

1 July 2015 http://erc.endocrinology-journals.org DOI: 10.1530/ERC-15-0261
(C) 2015 Society for Endocrinology Printed in Great Britain
Published by Bioscientifica Ltd 